\title{
MICROSURGICAL APPROACH OF ARTERIOVENOUS MALFORMATIONS IN THE CENTRAL LOBULE
}

\author{
Feres Chaddad-Neto', Andrei Fernandes Joaquim², Marcos Juliano dos Santos ${ }^{2}$, \\ Paulo Wagner Linhares², Evandro de Oliveira ${ }^{3}$
}

\begin{abstract}
Arteriovenous malformations (AVM) are neurovascular disorders that occur mainly in young adults. Their clinical presentation is variable and depends on its location, size and occurrence of bleeding. They can represent incidental findings in neuro radiological exams. The treatment of these lesions when located in eloquent areas, namely around the central sulcus, is controversial, with different therapeutical approaches presented in the literature. We consider that surgical extirpation of many of these lesions is feasible in selected cases, when supported by profound anatomical knowledge and refined microsurgical technique, achieving cure with minimal aditional deficit. In the present article, we elaborate a surgical technique for the approach of AVMs located in the central sulcus, specially in finding the topographic lesion location and craniotomy.
\end{abstract}

KEY WORDS: central sulcus, central lobule, arterio-venous malformation, craniotomy.

\begin{abstract}
Abordagem microciúrgica para malformações arteriovenosas no lóbulo central
Resumo - Malformações arteriovenosas (MAV) são uma entidade patológica que ocorre mais frequentemente em adultos jovens. Sua manifestação clínica é variável e depende de sua localização, tamanho e ocorrência ou não de sangramento. Podem também ser diagnoticadas como achados incidentais em investigações neurorradiólogicas . O tratamento destas lesões, quando localizadas em áreas eloqüentes, em particular aquelas lesões localizadas próximas ao sulco central do cérebro, é controverso e diferentes abordagens terapêuticas são relatadas. Consideramos que a ressecção cirúrgica destas lesões é viável em casos selecionados, quando realizada sob profundo conhecimento anatômico e técnica microcirúrgica refinada, pois deste modo, as lesões podem ser curadas sem agregar morbidade ao paciente. No presente artigo, discutimos a técnica cirúrgica para MAVs localizadas nas adjacências do sulco central do cérebro, especialmente a localização topográfica da lesão e craniotomia.
\end{abstract}

PALAVRAS-CHAVE: sulco central, lóbulo central, malformação arteriovenosa, craniotomia.

Arteriovenous malformations (AVM) are neurovascular pathologies that occur mainly in young adults. Their clinical manifestations are variable, like seizures, headache, progressive neurological deficits, rupture with intraventricular or subarachnoid haemorrhage or represent incidental findings of neuroimaging exams. AVM therapeutic orientation should be defined by a multidisciplinary team in reference centers and the results must be better then the disease's natural history to justify its treatment. Microsurgical resection is the definite treatment for these lesions.

AVMs classified as Spetzler-Martin' grade I and II should be approached surgically. Spetzler-Martin' grade III enclosures AVMs of distinct characteristics which leads to tremendous therapeutic implications. A subdivision of this group as already been proposed by the senior author. AVMs grade IIIA (volumous cortical lesions with superficial drainage or medium size AVMs in eloquent areas) are operated after endovascular procedure. AVMs grade IIIB (small and located in the limbic lobe) due to its proximity with basal cisterns are also dealt with surgery. The majority of AVMs grade IIIC (AVMs of the insular bloc and feeding by the lenticular-striate arteries) are treated with radiosurgery. Even these, in a small number located in caudate nucleus head, pulvinar thalami, claustrum and insular cortex can also be approached microsurgically with good results. Grades IV e V treatment is usually conservative ${ }^{2}$, reserving the surgical approach, after previous endovascular pro-

Neurosurgery Division of Neurology and Neurosurgery Department, Campinas State University (UNICAMP), Campinas SP, Brasil: ${ }^{1}$ Neurosurgeon from Institute of Neurological Sciences (ICNE) and Beneficência Portuguesa Hospital, São Paulo SP, Brazil and from UNICAMP; ${ }^{2}$ Resident of Neurosurgery from UNICAMP; ${ }^{3}$ Chief of Microneurosurgery Laboratory, Beneficência Portuguesa Hospital and the ICNE. Chief of Neurosurgery Division, UNICAMP. 

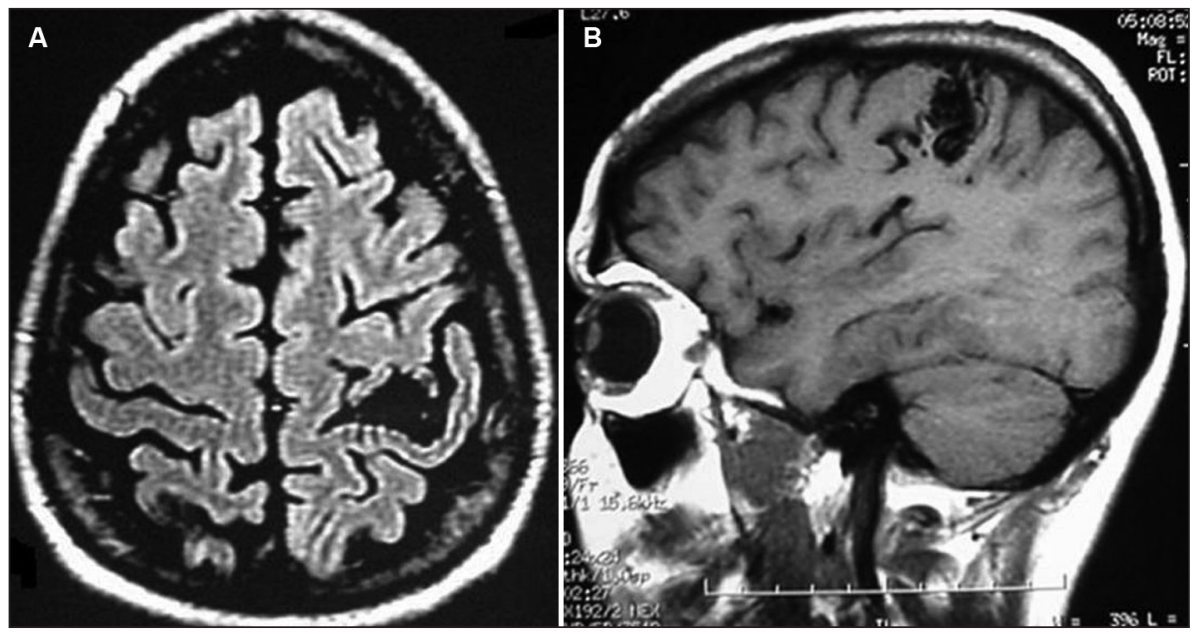

Fig 1. (A) The MRI helps localizing the lesion. Axial flair magnetic resonance imaging revealing hiposignal area in the central sulcus. (B) Sagittal T7WI showing hiposignal area in the central sulcus in sagital image.

cedure, to those patients with progressive neurological deficit, recurrent bleedings or intracranial hypertension.

Endovascular procedures are an important complement of surgery when dealing with AVMs, but the cure obtained by this modality alone occurs only in a minority of cases. Radiosurgery can be used in small, deep, and in eloquent areas AVMs, but the approximate two year latency to obtain the lesion obliteration carries the risk of haemorrhage during this period. The central lobule of the brain is formed by the precentral and postcentral gyri and central sulcus. Its anterior limit is the pre-central sulcus and the postcentral sulcus is the posterior limit. The superior margin of the brain is the superior limit of the central lobule, separating it from the paracentral lobule. Inferiorly, the sylvian fissure, or lateral sulcus of the brain, limits the central lobule. Besides the angiogram, the pre-operative magnetic resonance imaging (MRI) of the brain, especially the T1W1 sequence, is very usefull in refining the anatomic details of the adjacent brain and and sulci, thus, helping to find the exact location of the AVM (Fig 1).

Considerations can be drawn when AVMs are located in eloquent cortical areas, especially in the central lobule, empathized in the present study.

\section{THERAPEUTIC ASPECTS}

Concerning non-surgical treatment, several studies like those by Andrade-Souza et al. ${ }^{3}$ and Hadjipanavis et al. ${ }^{4}$ evaluated the prognosis of patients with AVM located in primary motor and sensitive areas treated with radiosurgery, concluding that this is the treatment of choice for lesions located in eloquent areas. However, its efficacy is limited to AVMs with less than 3 centimetres and, during the time necessary to obliterate these lesions (approximately 2 years) the patient remains unprotected against haemorrhagic events. Its long term morbidity is dose-dependent and vascular injury and radionecrosis from the procedure may result in neurological deficits.

In a different way, some authors reported that neurophysiologic intra-operative monitoring makes the surgical procedure in eloquent areas safer. Kombos et al. ${ }^{5}$, advocated the use of intra-operative monitoring for the identification of sensitive and motor areas, through somato-sensorial evoked potentials. Ebeling et al. ${ }^{6}$, presented low incidence of neurological deficits in 50 patients with different lesions located in the primary motor and adjacent areas with the use of cortical stimulation and evaluation of intra-operative. Firsching et al. ${ }^{7}$, also suggested that somato-sensorial evoked potentials utilization is useful in identifying post-central girus in central sulcus region areas.

In this way, we verify that there is no consensual conduct in AVM treatment, especially those located in eloquent areas.

With microsurgical technique development, improvements in neuroradiology, neuroanesthesia and intra and postoperative monitoring, the approach of these lesions is feasible. We believe that many of the lesions located in the central sulcus region can be safely approached surgically and cured if the removal is based upon anatomical data and refined microsurgical technique, despite the treatment with radiosurgery preconized as first line for some authors. The eventual post-operative deficits are usually transitory, and constitute no contraindication for the surgical procedure (Fig 2).

In the present study, we elaborate on the surgical technique for the approach of AVMs located in the central sulcus, especially in finding the topographic lesion location and craniotomy. 


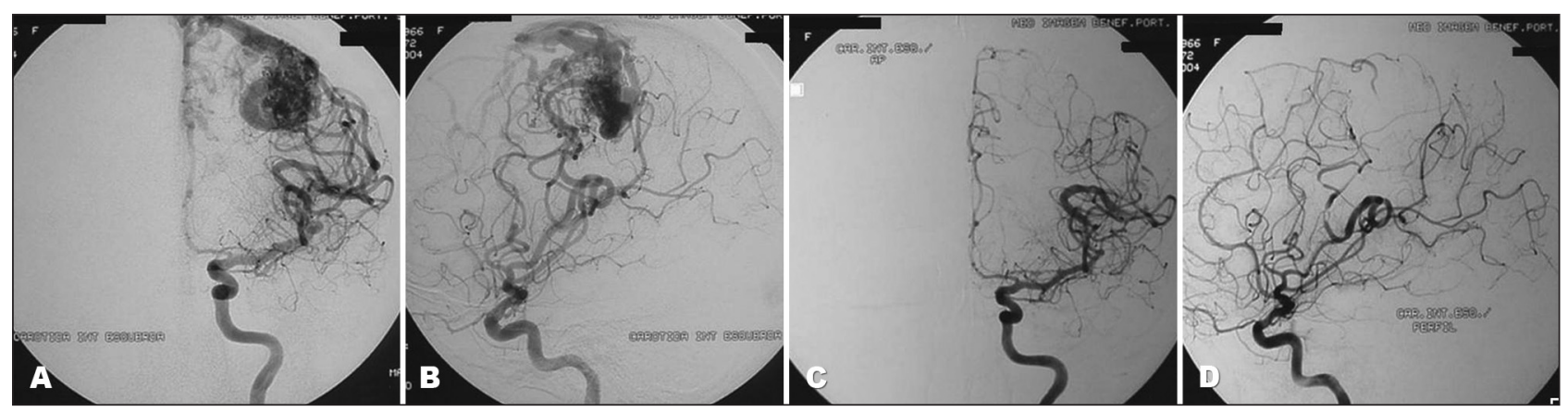

Fig 2. Anterior-to-posterior and lateral angiogram showing AVM feeding by the medium and anterior cerebral arteries, with a big draining vein to the superior sagital sinus, located in the central sulcus. (A, B) Before operation; (C, D) After operation.

\section{CRANIAL ANATOMIC KEY-POINTS}

Cranial topographic knowledge is fundamental to perform an adequate craniotomy ${ }^{8}$.

The main points for the approach of lesions in the central sulcus region are identified bellow.

Anterior sylvian point - Located in the inferior part of the pars triangularis and in the antero-inferior region of the pars opercularis of the inferior frontal girus, causing a focal enlargement of the sylvian fissure, with cisternal characteristics. Its relation with the external cranial surface is in the most anterior region of the squamous suture (superiorly to the spheno-squamous suture and immediately posterior to the sphenoparietal suture) ${ }^{8}$.

Central sulcus - Generally a continuous sulcus without connection with any other anteriorly or posteriorly. Its superior extremity is located in the inter-hemispheric fissure.

The intersection of the central sulcus with the interhemispheric fissure is called superior rolandic point. The region of its projection in the cranium is approximately $5 \mathrm{~cm}$ behind the bregma, which is located $12 \mathrm{~cm}$ behind the nasion ${ }^{8}$.

The inferior rolandic point corresponds to the intersection of the central sulcus with the sylvian fissure, real or projected. Its correspondence in the cranium is in the region of intersection of the squamous suture with a vertical line projected from the pre-auricular depression ${ }^{8}$.

The region of the encounter between the superior frontal sulcus and the precentral sulcus is also important in the surgical planning. It is located about $1-2 \mathrm{~cm}$ posterior the coronal suture and $2-3 \mathrm{~cm}$ lateral to the sagital suture (Superior Coronal Point) ${ }^{8}$.

The region of the encounter between the inferior frontal sulcus and the precentral sulcus, is located where the superior temporal line joins the coronal suture, in a craniometric point called Stephanion ${ }^{8}$.

The Euryon is a craniometric point centred in the parietal tuberosity. It corresponds internally to the supramarginal gyrus region, posterior to the central sulcus e superior to the posterior sylvian point ${ }^{8}$.
The intraparietal point is located $5 \mathrm{~cm}$ anterior and 4 $\mathrm{cm}$ lateral to the lambda as pointed by Gusmão et al..

\section{SURGICAL PROCEDURE}

Patients must be supine, with the head in neutral position above the level of the heart to improve venous drainage. The pin of the head holder on the side of the lesion is positioned in the mastoid and the contra-lateral pins in the superior temporal line, avoiding the temporal muscle

The hair is shaved as represented in Figure 3, crossing the midline, with better cosmetic effect and without compromising the closure of the skin.

When marking the incision, one must define the regions of the pre-central sulcus and the superior rolandic, inferior rolandic, superior coronal and intraparietal points. The use of skin retractors helps in the exposure and haemostasis.

The craniotomy must be wide, after exposure of the coronal and sagittal sutures for orientation of the regions described above (Fig 3).

The dural opening is made under microscopic visualization, $U$ shapped, with its base in the superior sagital sinus, being folded over it, carefully no to damage cortical or AVM venous drainage structures. This must expose not only the AVM but also the surrounding normal brain tissue, allowing the correct identification of the vessels, sulci, gyri and central lobule (Fig 3).

Brain retraction is kept to the minimum necessary and the arachnoid plane is respected to avoid damaging the normal cerebral tissue and penetration into the AVM nidus. As in all microsurgical procedures, the operating field must be kept free from haemorrhages that infiltrate the arachnoid and pial plane masking the anatomical references. Then, properly arachnoid dissection is performed, identifying the drainage vein, which comes from the AVM nidus. Careful bipolar coagulation of feeding vessels must be performed as close as possible to the lesion, after as- 

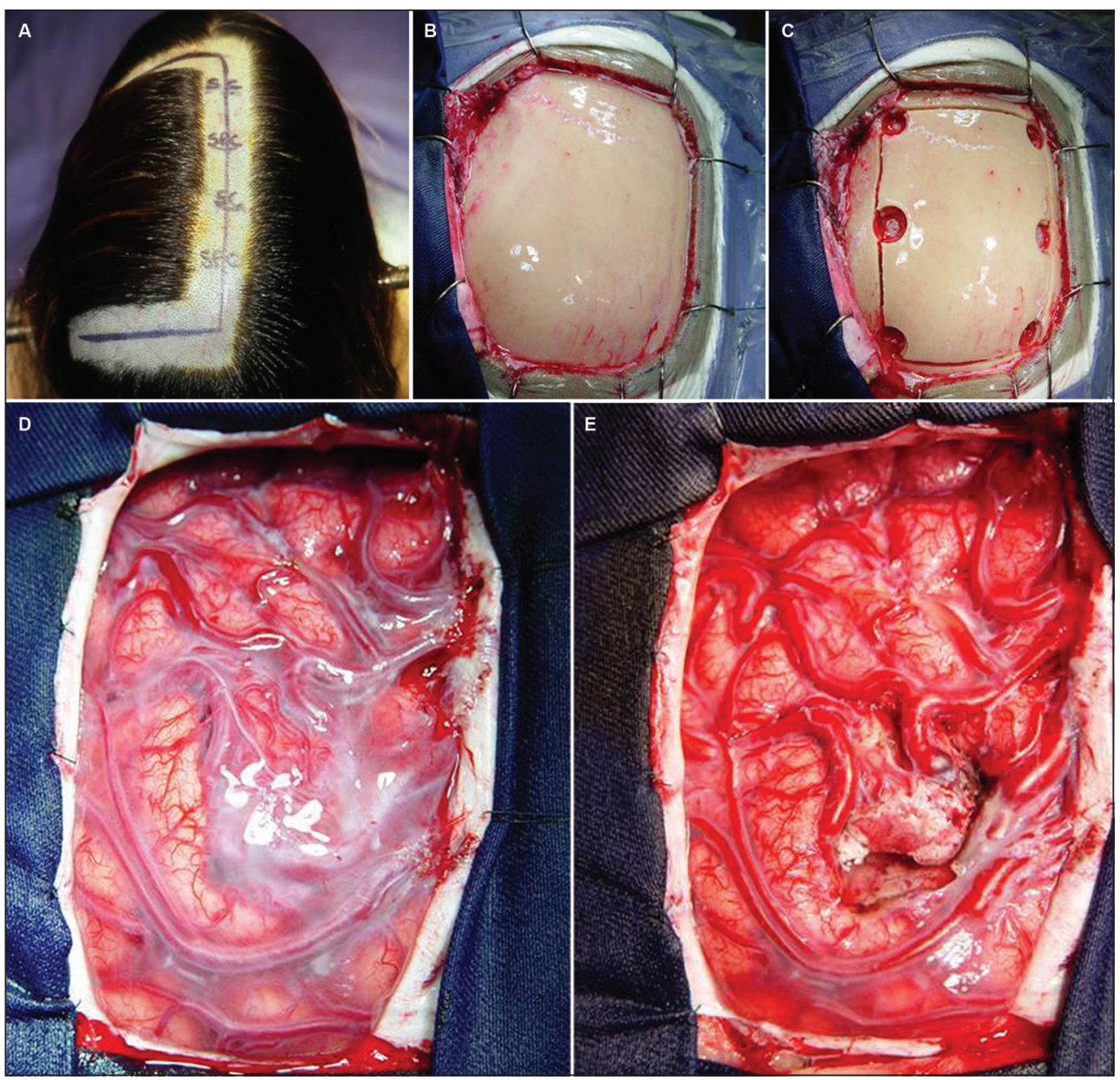

Fig 3. (A) Tricotomy and marking of the coronal suture and left superior rolandic point region. Legend (from rostral to dorsal) SC, coronal suture; SPC, pre-central sulcus, approximately $3 \mathrm{~cm}$ posterior to the bregma; SC, central sulcus (superior rolandic point); SPC, post-central sulcus, about $2 \mathrm{~cm}$ posterior to the central sulcus. (B) Cranial exposure, showing the sagittal and coronal sutures. (C) Bone flap ready for removal. (D) Complete exposure of a grade II Spetzler-Martin AVM of the central sulcus region. (E) Surgical site after removal of the AVM. suring that they are not just passing through de AVM to supply adjacent and eloquent brain tissue, the "en passage" vessels, always reminding that the feeding arteries of the AVM have fragile walls and are of difficult obliteration. The feeding vessels of central sulcus AVM usually come from the middle cerebral artery (M4 segment). As we know, the same dissection plane must be kept during the whole procedure to ensure the surgeon not to injury the brain tissue and neither enters the AVM nidus. When the AVM shrinks due to obliteration of its feeders, it is resected after coagulating its venous drainage, which can be more than one and usually drains to superior sagital sinus and/or superficial sylvian vein.

In conclusion, cranial topography should be used for locating the central sulcus region, complementing neurophysiologic studies. Profound anatomic knowledge and refined microsurgical technique are the bases for the surgical treatment of lesions in this region. Neurosurgical procedure performed in reference centres by trained professionals, supported by a multidisciplinary team can be con- sidered as the first line treatment for many AVMs located in eloquent areas.

\section{REFERENCES}

1. Spetzler RF, Martin NA. A proposed grading system for arteriovenous malformations. J Neurosurg 1986;65:476-483.

2. De Oliveira E, Tedeschi H, Raso J. Multidisciplinary approach to arteriovenous malformations. Neurol Med Chir (Tokyo) 1998;38(Suppl): S177-S185.

3. Andrade-Souza YM, Ramani M, Scora D, Tsao MN, TerBrugge K, Schwartz ML. Radiosurgical treatment for rolandic arteriovenous malformations. Neurosurgery 2006;105:689-697.

4. Hadjipanayis CG, Levy EI, Niranjan A, et al. Stereotactic radiosurgery for motor cortex region arteriovenous malformations. Neurosurgery 2001;48:70-76.

5. Kombos T, Suess O, Funk T, Kern BC, Brock M. Intra-operative mapping of the motor cortex during surgery in and around the motor cortex. Acta Neurochir (Wien) 2000;142:263-268.

6. Ebeling U, Schmid UD, Ying H, Reulen HJ. Safe surgery of lesions near the motor cortex using intra-operative mapping techniques: a report on 50 patients. Acta Neurochir (Wien) 1992;119:23-28.

7. Firsching R, Klug N, Borner U, Sanker P. Lesions of the sensorimotor region: somatosensory evoked potentials and ultrasound guided surgery. Acta Neurochir (Wien) 1992;118:87-90.

8. Ribas GC, Yasuda A, Ribas EC, Nishikuni K, Rodrigues Jr. A J. Surgical anatomy of microneurosurgical sulcal key points. Neurosurgery 2006;59:177-211.

9. Gusmão S, Silveira RL, Arantes A. Pontos referenciais nos acessos cranianos. Arq Neuropsiquiatr 2003;61:305-308. 